\title{
REVACCINATION PROGRAM POST-HEMATOPOIETIC STEM CELL TRANSPLANTATION AND COVID-19 VACCINE: CURRENT CHALLENGES
}

\author{
Dr. Clarisse M. Machado 1,2,3
}

1. Laboratório de Virologia, Instituto de Medicina Tropical, Faculdade de Medicina da Universidade de São Paulo, São Paulo, SP
2. Serviço de TMO, Fundação Hospital Amaral Carvalho, Jaú, SP
3. Instituto Israelita de Ensino e Pesquisa - IIEP - Hospital Israelita Albert Einstein, São Paulo, SP

Hematopoietic stem cell transplantation (HSCT) is a therapeutic modality that has been used for the treatment of various diseases and hematological neoplasms for decades. HSCT is a long, individualized, and highly complex process that requires multidisciplinary skills. HSCT starts much earlier and extends far beyond the infusion of the hematopoietic stem cells. Regardless of the type of transplant to be performed, autologous or allogeneic, before graft infusion, total or partial ablation of the bone marrow's immunohematopoietic elements is necessary, a procedure known as conditioning regimen.

After conditioning, HSCT recipients lose immune memory to infectious agents and vaccines accumulated throughout life. Post-HSCT immune reconstitution is slow and may be affected by other pre- and post-HSCT events, such as the drugs used to treat the underlying disease, the source of progenitor cells, the prophylaxis or treatment of graft-versushost disease (GVHD), among others ${ }^{(1)}$.

After HSCT, antibodies against vaccine-preventable diseases gradually wane over time, leaving the recipient susceptible to these diseases, if not revaccinated. One year after HSCT, about $60 \%$ of patients lose antibodies against diphtheria, 50\% against tetanus, $35 \%$ against measles, 33\% against polio and $24 \%$ against hepatitis $A$, with slight variations between published studies ${ }^{(2-7)}$.

Although the response to vaccines is usually inferior in this population, post-HSCT revaccination is necessary to enable the reconstitution of lost immunity, protection against infections that are potentially lethal in these patients and to ensure the same protection offered to the general population.

Since 1995, revaccination protocols post-HSCT have been proposed through international consensus and revised by experts ${ }^{(8-11)}$. Such programs must be adapted regionally, taking into account the local epidemiological situation. The most recent international guideline on this topic was published in 2019 by the working group of the European Conference on Infections in Leukemia (ECIL) ${ }^{(12)}$.

In Brazil, the first recommendations on HSCT revaccination program emerged in 1992, at the initiative of a few transplant centers. At that moment, there were no agencies with specific infrastructure and logistics to care for individuals with special clinical conditions. In 1993, the National Immunization Program (PNI) created the Reference Centers for Special Immunobiologicals (CRIE), following the basic principles of universality and equity of the Unified Health System (SUS). A recent publication of the CRIE Manual describes a proposal for a revaccination program for the HSCT recipient, offering through the country and free of charge, most of the vaccines recently proposed by the Brazilian Society for Blood and Marrow Transplantation and Cellular Therapy (SBTMO) ${ }^{(13,14)}$.

Despite the spectacular vaccine program made available by the Ministry of Health through PNI and CRIE, HSCT recipients have difficulties in complying with the revaccination schedule, which invariably result in delays and failure to complete the proposed scheme.

The revaccination program is complex since it involves 12 to 14 different vaccines, with multiple doses (except for the inactivated vaccine against influenza in those over 9 years old), different intervals between doses and restrictions of attenuated vaccines in certain circumstances. To achieve the expected outcome, the program involves three phases that must act synergistically, namely: 1) the correct referral for vaccination by the HSCT center; 2) patient or guardian's adherence to the orientation of the transplant center; and 3) compliance with the schedule proposed by those responsible for the reg- 
istration and application of the vaccines, in private clinics, CRIE, basic health units (UBS) or vaccination rooms ${ }^{(15)}$.

Unfortunately, the perfect coordination of these actions has not yet been achieved. According to a national study, delays in the revaccination program were observed in about $80 \%$ of the participants, the majority due to failures by the transplant center in referring the patient for vaccination or in the application of vaccines in the vaccination sites. The lack of compliance by the patient or guardian was observed in a small frequency (15). Therefore, it is clear that efforts to ensure the success of the revaccination program must focus mainly on educational activities at HSCT centers and on greater integration of HSCT centers with CRIE and vaccination sites.

In view of the pandemic and the prospect of starting COVID-19 vaccination for groups with comorbidities, which include transplant recipients, the reported problems anticipate the challenges to come, which are added to the difficulties already inherent to the revaccination program.

So far, we have more questions than answers: Which vaccine against COVID-19 is the safest, the most effective, the best time to vaccinate, how many doses will be needed, when to vaccinate recipients with graft versus host disease (GVHD), how often the vaccine will be introduced into the revaccination calendar, among others. However, these questions need time to be answered.

Despite the scarcity of studies in immunocompromised patients, a few publications indicate that these patients should be monitored carefully after vaccination.

A recent study in solid organ transplant (SOT) recipients showed that at a median of 20 (17-24) days after the first dose of vaccine, SARS CoV-2 antibodies were detectable in 76 of 436 SOT recipients $(17 \% ; 95 \% \mathrm{Cl}$, $14 \%-21 \%)$ who received mRNA BNT162b2 vaccine (Pfizer-BioNTech) or mRNA-1273 vaccine (Moderna). After the first dose, significantly better response was observed in younger patients, in those receiving Moderna in comparison with Pfizer-BioNTech vaccine ( $69 \%$ vs $31 \%$, respectively), and in those not receiving anti-metabolite immunosuppression (63\% vs $37 \%)$, respectively ${ }^{(16)}$.

Del Bello et al., reported a case of acute rejection in a kidney transplant recipient 8 days after the second dose of Pfizer-BioNTech vaccine and suggest careful monitoring of organ rejection in SOT recipients undergoing anti-SARS-CoV-2 vaccination ${ }^{(17)}$.
At the moment, the vaccines approved by ANVISA for use in Brazil (Coronavac, Oxford-Astrazeneca, Pfizer-BioNtech and Janssen) are considered safe and can be used in HSCT recipients. Inactivated vaccines such as the Coronavac have been used for decades in HSCT recipients (e.g. influenza vaccine). However, non-replicating viral vector vaccines (Oxford-Astrazeneca and Janssen) and mRNA vaccines (Pfizer-BioNtech) have never been used in this population. Therefore, careful and close monitoring of vaccinated patients is recommended.

Due to the high transmission rates still observed in Brazil and the greatest severity and lethality of COVID-19 in HSCT recipients, the SBTMO recommends vaccinating patients with any available vaccine, ideally after the 6th month of HSCT when a better response to vaccine is expected. However, in regions with accelerated rates of transmission, vaccination may be anticipated from the 3rd month of transplantation. A summary of the SBTMO recommendations can be seen in figure 1 .

It is important to note that the studies conducted with the available COVID-19 vaccines have not included immunocompromised populations, and therefore, the efficacy is unknown in these patients. HSCT recipients should be aware of this and be encouraged to maintain the preventive measures, even after vaccination. The greatest risk of transmission of COVID-19 is at home and even vaccinated, HSCT recipients may have a weaker antibody response. Therefore, household contacts should also receive COVID-19 vaccine. However, due to the lack of vaccines, only household contacts with comorbidities are eligible to receive the vaccine and should be encouraged to do so.

The Ministry of Health is in charge of COVID-19 vaccine distribution to the states. Therefore, once vaccination dates for HSCT recipients have been announced, transplant centers should refer patients to receive the vaccine. Despite the unassertive attempts to recover the vaccination delay caused by the disastrous management of the pandemic in Brazil, the vaccination campaign against COVID-19 remains slow, with numerous challenges to be overcome, such as the interruptions due to lack of vaccines, fraud in the administration or exchange of vaccines, lack of the second dose, among others.

The long-awaited time for COVID-19 vaccination of HSCT recipients has arrived. We hope that the lack of a central and unique vaccination guidance for this large group of people with comorbidities does not hinder the ultimate goal of protecting these patients at high risk of COVID-19 complications. 


\begin{tabular}{|l|l|} 
HSCT recipients should be vaccinated with any of the approved COVID-19 vaccines available in Brazil. \\
At this time, it is recommended to prioritize vaccination against COVID-19, and wait at least 2 weeks for the \\
administration of other vaccines. \\
Careful and close monitoring of vaccinated patients is recommended since some of the available vaccine platforms \\
(non-replicant viral vector and mRNA vaccines) have never been used in transplant patients.
\end{tabular}

FIGURE 1 - SBTMO recommendations for COVID-19 vaccination of HSCT recipients and information concerning donors vaccinated before donation ${ }^{(18)}$.

\section{REFERENCES}

lishing; 2019 [cited 2021 May 13]. 689 p. Available from: http://link.springer.com/10.1007/978-3030-02278-5

2. Parkkali T, Ruutu T, Stenvik M, Kuronen T, Käyhty $\mathrm{H}$, Hovi T, et al. Loss of protective immunity to polio, diphtheria and Haemophilus influenzae type b after allogeneic bone marrow transplantation. Apmis. 1996;104(5):383-8.

3. Ljungman $P$, Wiklund-Hammarsten $M$, Duraj $V$, Hammarström L, Lönnqvist $B$, Paulin $T$, et al. Response to tetanus toxoid immunization after allogeneic bone marrow transplantation. J Infect Dis. 1990;162(2):496-500.

4. Ljungman $P$, Aschan J, Barkholt L, Broliden P, Gustafsson B, Lewensohn-Fuchs I, et al. Measles immunity after allogeneic stem cell transplantation; influence of donor type, graft type, intensity of conditioning, and graft-versus host disease. Bone Marrow Transplant. 2004;34(7):589-93.

5. Machado CM, Gonçalves FB, Pannuti CS, Dulley $\mathrm{FL}$, Souza VA. Measles in bone marrow transplant recipients during an outbreak in São Paulo, Brazil. Blood. 2002;99(1):83-7.
6. Godoi ER, Souza VA, Cakmak S, Machado AF, Vilas Boas LS, Machado CM. Loss of hepatitis A virus antibodies after bone marrow transplantation. Bone Marrow Transplant. 2006;38(1):37-40.

7. Adati EM, Silva PM, Sumita LM, Rodrigues MO, Zanetti LP, Santos AC, et al. Poor response to hepatitis $A$ vaccination in hematopoietic stem cell transplant recipients. Transpl Infect Dis. 2020;22(3):1-6.

8. Ljungman $P$, Engelhard D, Cámara R, Einsele H, Locasciulli A, Martino R, et al. Vaccination of stem cell transplant recipients: recommendations of the Infectious Diseases Working Party of the EBMT. Bone Marrow Transplant. 2005;35(8):737-46.

9. Ljungman $P$, Cordonnier $C$, Einsele $H$, Englund J, Machado CM, Storek J, et al. Vaccination of hematopoietic cell transplant recipients. Bone Marrow Transplant. 2009;44(8):521-6.

10. Machado CM. Reimmunization after hematopoietic stem cell transplantation. Expert Rev Vaccines. 2005;4(2):2019-28.

11. Kamboj M, Shah MK. Vaccination of the Stem Cell Transplant Recipient and the Hematologic Malignancy Patient. Infect Dis Clin North Am. 2019;33(2):593-609. 
12. Cordonnier C, Einarsdottir S, Cesaro S, Di Blasi R, Mikulska M, Rieger C, et al. Vaccination of haemopoietic stem cell transplant recipients: guidelines of the 2017 European Conference on Infections in Leukaemia (ECIL 7). Lancet Infect Dis. 2019;19(6):e200-12.

13. Ministério da Saúde (Brasil). Secretaria de Vigilância em Saúde. Manual Dos Centros de Referencia para Imunobiológicos Especiais [Internet]. 5a ed. Brasilia DF; 2019 [cited 2021 May 13]. Available from: https://portalarquivos2.saude. gov.br/images/pdf/2019/dezembro/11/manual-centros-referencia-imunobiologicos-especiais-5ed.pdf

14. Maiolino MG, Carlesse F, Ramos JF, Machado CM. Prevention and treatment of infectious complications post HSCT. JBMTCT. 2021;4(1):197-217.

15. Silva PM, Silva ÉM, Simioni AJ, Souza MP, Colturato VAR, Machado CM. Difficulties in the revaccination program of hematopoietic stem cell transplantation recipients. Rev Inst Med Trop Sao Paulo. 2017;59(2):87-98.
16. Boyarsky BJ, Werbel WA, Avery RK, Tobian AA, Massie $A B$, Segev DL, et al. Immunogenicity of a Single Dose of SARS-CoV-2 Messenger RNA Vaccine in Solid Organ Transplant Recipients. JAMA. 2021;325(17):1784-6.

17. Del Bello A, Marion O, Delas A, Congy-Jolivet N, Colombat M, Kamar N. Acute rejection after anti-SARS-CoV-2 mRNA vaccination in a patient who underwent a kidney transplant. Kidney Int. 2021;110(2):697-700.

18. Agência Nacional de Vigilância Sanitaria (ANVISA). Nota Técnica no 13/2021/SEI/GSTCO/DIRE1/ ANVISA. Orientações sobre inaptidão temporária para doação de células-tronco hematopoiéticas (CTH) para fins de transplante convencional de candidatos a doação que foram submetidos a vacinação contra a Covid-19. [Internet]. Brasília: SEl; 2021 [cited 2021 May 13]. Available from: http://redome.inca.gov.br/wp-content/uploads/2021/02/nota-tecnica-13-gstco-doacaocth-e-vacinacao-contrta-covid19-1.pdf 